\title{
MEMORANDUM
}

No 20/2007

\section{A Journey for Your Beautiful Mind: Economics Graduate Study and Research}

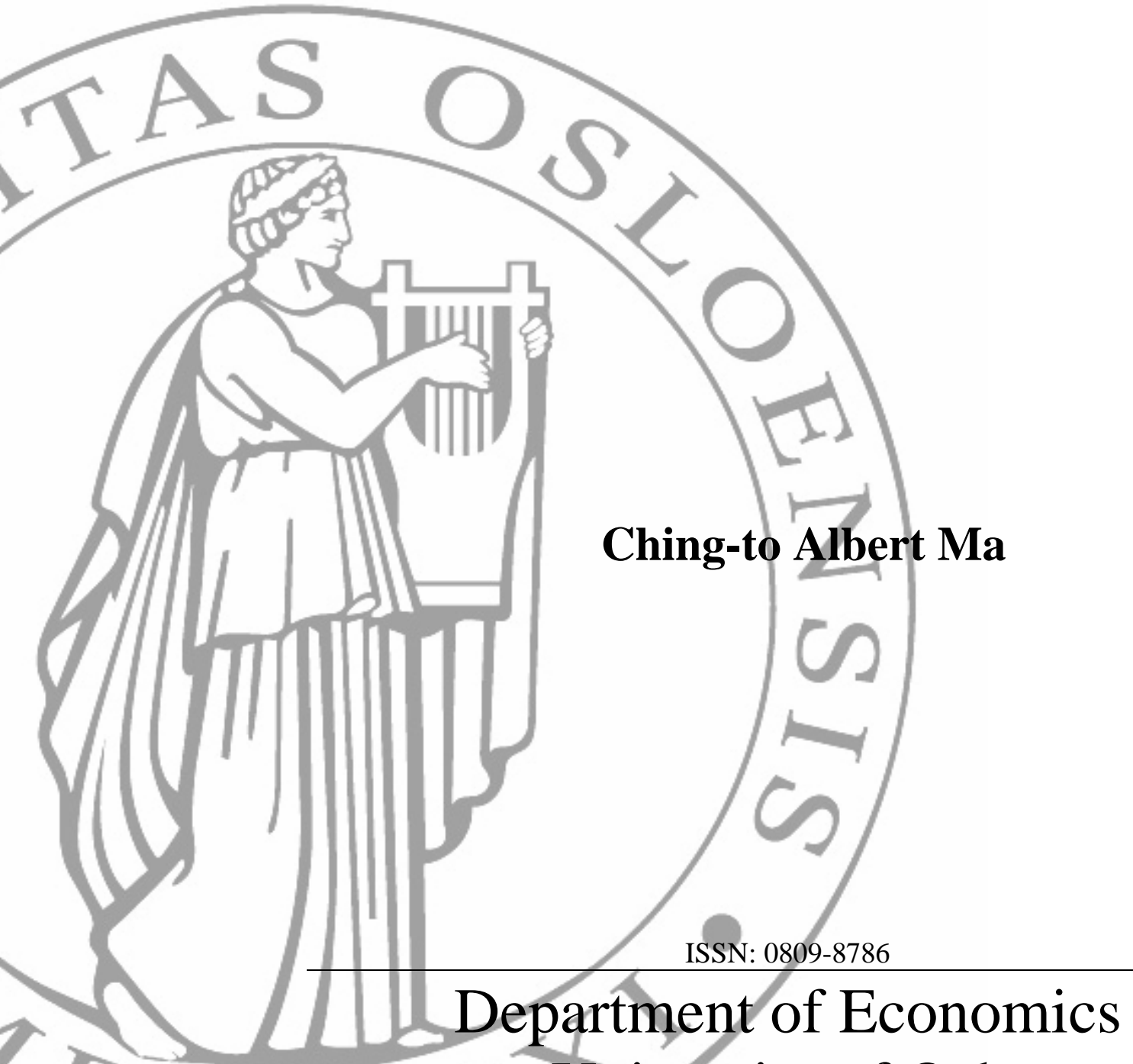

University of Oslo 
This series is published by the

\section{University of Oslo}

Department of Economics

P. O.Box 1095 Blindern

N-0317 OSLO Norway

Telephone: + 4722855127

Fax: $\quad+4722855035$

Internet: http://www.oekonomi.uio.no

e-mail: $\quad$ econdep@econ.uio.no
In co-operation with

The Frisch Centre for Economic

Research

Gaustadalleén 21

N-0371 OSLO Norway

Telephone: $\quad$ +4722958820

Fax: $\quad+4722958825$

Internet: $\quad$ http://www.frisch.uio.no

e-mail: $\quad$ frisch@frisch.uio.no

\section{Last 10 Memoranda}

\begin{tabular}{cl}
\hline No 19/07 & $\begin{array}{l}\text { Simen Markussen } \\
\text { Trade-offs between health and absenteeism in welfare states: striking } \\
\text { the balance }\end{array}$ \\
\hline No 18/07 & $\begin{array}{l}\text { Torbjørn Hægeland, Oddbjørn Raaum and Kjell Gunnar Salvanes } \\
\text { Pennies from heaven - Using exogenous tax variation to identify effects } \\
\text { of school resources on pupil achievement }\end{array}$ \\
\hline No 17/07 & $\begin{array}{l}\text { B. Bratsberg, T. Eriksson, M. Jäntti, R. Naylor, E. Österbacka, } \\
\text { Marital Sorting, Household Labor Supply, and Intergenerational } \\
\text { Earnings Mobility across Countries }\end{array}$ \\
\hline No 16/07 & $\begin{array}{l}\text { Kjell Arne Brekke, Gorm Kipperberg and Karine Nyborg } \\
\text { Reluctant Recyclers: Social Interaction in Responsibility Ascription }\end{array}$ \\
\hline No 15/07 & $\begin{array}{l}\text { F. R. Førsund, S. A. C. Kittelsen and V. E. Krivonozhko } \\
\text { Farrell Revisited: Visualising the DEA Production Frontier }\end{array}$ \\
\hline No 14/07 & $\begin{array}{l}\text { Q. Farooq Akram and Ragnar Nymoen } \\
\text { Model selection for monetary policy analysis - How important is } \\
\text { empirical validity? }\end{array}$ \\
\hline No 10/07 & $\begin{array}{l}\text { Knut Røed and Lars Westlie } \\
\text { Unemployment Insurance in Welfare States: Soft Constraints and Mild } \\
\text { Sanctions }\end{array}$ \\
\hline Labor Market Transitions and Job Durations for Immigrants
\end{tabular}

A complete list of this memo-series is available in a PDF® format at: http://www.oekonomi.uio.no/memo/ 


\title{
A Journey for Your Beautiful Mind:
}

\section{Economics Graduate Study and Research}

A lecture to graduate students of the joint Economics Ph.D. program of the Department of Economics, University of Bergen, and the Norwegian School of Economics.

\author{
Ching-to Albert Ma \\ Department of Economics \\ Boston University and University of Oslo
}

August 24, 2007

Bergen, Norway

Acknowledgement: Many friends, colleagues and students inspired me. My thanks to Ingela Alger, Lucia Chung, Randy Ellis, Jacob Glazer, Simona Grassi, Miriam Hatoum, Michael Hoel, Tor Iversen, Bart Lipman, Ting Liu, Tom McGuire, Michael Manove, Debby Minehart, Dilip Mookherjee, Claudia Olivetti, Ariel Rubinstein, Fred Schroyen, Kam-wing Siu, Monic Sun, and Cecilia Wan for their comments on earlier drafts. 
You must be very excited, ready to start your Ph.D. program here in Bergen. To many of you this will be an important milestone. It should be. Undertaking a Ph.D. study is not a trivial matter, and I hope that you do take this seriously.

I have been asked to address you on matters concerning modern economics and your upcoming study and research. This is a daunting task. First, modern economics is a huge subject. Second, graduate study and research in economics is also a huge subject. Early on I have come to the conclusion that your professors here have given me a mission impossible, but I'll try my best in the next hour or so.

Let me first say that my own research is mainly on applied microeconomic theory. My experience with empirical research is very limited. I probably don't have many useful things to say about handling data, selecting statistical software, etc. In other words, you are going to listen to some biased views, so beware.

\section{Modern Economics}

Once upon a time, an economist could stand up and say that economics is about the allocation of resources. I am afraid that that is history. Economists by now have done quite a bit more than resource allocations. If you pick up a recent economics journal, you'd see that the titles of the articles can seem rather strange. For example, in recent issues of the Journal of Economic Theory, you'd read titles such as

- Ambiguous events and maxmin expected utility

- Subjective probabilities on "small” domains

- Exploitation and time

- p-Best response set

But these strange titles are not limited to microeconomic theory. Look at the Journal of Monetary Economics, and you will find titles such as

- Do self-control preferences help explain the puzzling behavior of asset prices?

- Inattentive consumers

- Big elephants in small ponds: Do large traders make financial markets more aggressive?

Now some working papers are even less revealing. I have come across an economics working paper: “Are Working Women Good for Marriage?” You'd wonder when economists have started their dating or marriage counseling service. Or how about "Why We Grow Large, and then Grow Old: Economics, Biology and Mortality?” a working paper written by a very senior economist. If these titles are about economics, you must be thinking about a Ph.D. thesis on why Norwegians sing in their showers!

Such is the nature of modern economics. The word "price" almost never appears anywhere in the title of an article now. Often the word "price” doesn't even appear 
anywhere in the article. These days economics is much more than price and resource allocation. Nor is it only about inflation and employment. Economists have been trying to model many issues, some of which were previously the domain of political scientists, sociologists, psychologists, and anthropologists. The keyword is "model," a technique that is usually associated with abstraction, formalism, and mathematical and statistical techniques.

\section{Modeling: The Economist's Language}

I am sure that you will model something. Above all else, it is this general methodology that you will learn in the next few years. This is what modern economics is all about. I sometimes have the feeling that what makes a paper publishable in an economics journal is not what it is on, but how the analysis is done. It has to be done in a way that can be understood by economists. It can be on obesity, language, fish, global warming, procrastination, ambiguity, regret, the impending dooms-day prediction on the US social security system, or diversity of species. But they all share something in common. They share the same methodology.

Economists abstract; we simplify, and we analyze. There is a model, some model, which always carries some assumptions. It emphasizes some issues, and deemphasizes others. Then there are some auxiliary assumptions. After that, some analysis, be it mathematical or statistical. And then some results, conclusions, lessons learned. You will have to do that, very soon.

Sometimes economists begin with some institution, some experiments, and then data. We state our hypotheses, the identification method, and then the regression results. Or we use some calibration method to gauge how accurate a model fits the data. These are all common methods that economists understand. And you will have to learn them.

And that of course brings us to your mind. You see, most young minds are really not accustomed to thinking in terms of economic models. I'd like to illustrate this difficulty with an example Amartya Sen used.

John was lost and looking for the railway station. He came upon David, and asked David for direction. David said, "The station is just behind the post office. You will see it once you go past the post office. And by the way, would you mind putting this letter in the post office box when you go there?” John thanked David for the direction, took the letter, and started walking. But en route, John opened the letter to see if there was anything valuable!

Almost anyone would be appalled by these behaviors. I am sure that when you are asked for direction, you would not attempt to give an answer to convenience yourself, and when you are asked to mail a letter, you wouldn't open it to see if there is money inside. Most of us would not behave this way. Indeed, Sen said that someone who behaved exactly as economics predicted would be a social moron; such a person would not be able to 
function in society. But these behaviors are not surprising to economists. In fact, looking for gains in every possible way is exactly what economists aim to derive from their models---otherwise how could there be an equilibrium?

Let me give you another example. A labor economist was asked what was the most important determinant of employment. He said "wage." He was then asked what was the second most important determinant of employment. He thought for a second, and answered, "log of wage." To an ordinary person, perhaps the first answer is quite reasonable. But the second answer? Well, most would think about culture, job satisfaction, working hours, etc. Log of wage? It takes some courage, right? Perhaps it also shows how far abstraction can go.

When you were an undergraduate, you were taught how to read economics, understand books, maybe even study some research papers. Now that you enter a graduate program, you will be taught how to do economics. So first you have to understand how economists' minds work. They certainly work in a very peculiar way, abstracting away a lot of things from reality, concentrating on only a few things. It requires a lot of learning and experience to select what are the things you need to discard, and what the things to include in your models. In a nutshell, this is what you are going to do for the next few years, maybe even for your career after the Ph.D.: what to keep and what to discard.

What is it that your mind has to learn? There is a certain "maximizing" method for modeling economic behavior that is almost obscene, wrong, and outrageous. Yet, almost all economists embrace it. Though seemingly short-sighted and far-fetched, ours is a discipline that is based on some sort of beauty and simplicity.

I must add that "maximizing” behavior does not necessarily mean selfish behavior. Actually in recent years, economists have incorporated social preferences in their analysis. Economists often postulate that one cares about one's social status, other people's welfare, and fairness. Economic agents need not be entirely selfish, but they are almost always pursuing an objective.

What does this simple maximizing behavioral model buy you? You should ask this question, sooner than later. I do think that it buys you something, and that is consistency. Economists have developed a common methodology that is internally consistent for discussing many social issues. A big variety of social issues, topics that used to be in the domain of other social sciences. And you will have to learn to like and appreciate this consistency, this language that economists use.

\section{A Manual for Graduate Study}

For many students, success in school means success in exams. You are sitting here because you have done very well in exams. At the graduate school, you still have classes to do, and exams to take. You do have to pass some exams in order to continue with the program. However, for the Ph.D., classes and exams are only the beginning. Exams are 
really not what economics and the Ph.D. are about. You will have to go beyond exams, and produce original research.

By the way, I hate exams. I was fortunate enough not to have to go through qualifiers, and comprehensive exams that are so common in the US! I really don't have any exam tips for you. I have not thought about how to do exams for a very long time, and am not about to do it again.

Let me however emphasize that what you learn from the standard first-year graduate texts is very important. Your first-year texts give you the background to understand research papers, which will be the bulk of your economics graduate education. Such fundamental materials are not to be taken lightly. Do not study these texts only to pass exams, which would be unproductive.

\section{Papers}

The papers that you will read are probably all classics. These pieces have probably inspired a lot other works. Or they may have made headway in a research agenda. Make sure you understand why. The motivation of a paper is always very important. Then there may be new techniques, and new ways to study existing problems. Again, make sure you understand why.

Later in your program you may also read new, unpublished working papers. These are state-of-the-art, frontier pieces. Often they are exploratory, and may be very hard to read, because the corresponding literature may be immature and incomplete. But you still have to digest them, because very likely you will find inspiration in them for your own research.

There is no better way to understand a paper than by doing it yourself. Prove the propositions yourself. Work out the proofs. See the logic and the elegance of the arguments. Nothing is better than working out an example. Not an example that is in the paper, but rather an example that you construct yourself. This really puts you in the author's position. Your mind will be like the author's. You will have to go through the same creative process to get to the results. Your mind can really see what is going on.

You have to bear in mind that a finished paper may be only a fraction of the author's work for the project. A lot has been discarded, altered, revised, and improved to get to the final paper. But by working out an example, you may be able to have a glimpse of what has gone on behind the scene.

Finally, to convince yourself that you understand the paper, explain it to a fellow student. If you have read a micro paper, explain it to a student who is more interested in macro. If you have read a labor paper, explain it to someone more interested in environmental economics. You see, when you try to explain what a paper is all about, your mind really has to pretend that you are the author. See how HARD it is to explain a paper to others! If you can crystallize the paper's ideas into a few short sentences, that's a very good sign. 
You will read many, many papers. Even on the same topic, you will come across many pieces. Now the bad thing about the economics profession is that there is no universal notation, or convention. Laffont and Tirole use the cost of public fund; Baron and Myerson put more weight on consumer surplus and less on profit, while some simply take net consumer surplus as social welfare. Some use the utilitarian social welfare function, some use maxmin, and others use weighted utilitarian, etc.

A lot of confusions will occur when you read many papers. You will have to cut through the maze. You must obtain the general principles when papers differ in some technical and modeling details. You will have to decide that some differences between Laffont and Tirole and Baron and Myerson are insignificant, while others are critical. For some papers, the literature may have done this for you. Researchers that come after Laffont and Tirole and Baron and Myerson may have already sorted them out. For others, you may have to do the work yourself.

You seldom see the big picture by looking at one paper. You need to look at a set of papers. One paper usually focuses on one or two issues. Another paper then tackles another set of issues. But a class of problems contains more than a few. Let's look at public provision of a private good as an example. Why? How? What kind of asymmetric information? What kind of actions? How much tax burden? Can one or even two papers answer all of them? Unlikely. You are talking about a set of papers. All are about a general topic, but each one a little different. So you need a synthesis of papers in the literature in order to understand the topic really well. Read broadly, and understand papers in a generic way.

\section{Mathematics}

What about mathematics? You must have been wondering. There has been so much emphasis on mathematics in the admission process. How much mathematics should you learn for your Ph.D.? Economics can be very mathematical, and you may need a lot of mathematics to do mathematical economics. For most of the rest of economics, however, it isn't that mathematical. Nevertheless, most of economics does require a mathematical maturity that few undergraduates have managed to acquire.

What do I mean by mathematical maturity? Mathematical maturity does not only mean that you can do the n-th order derivative of any function, or find a closed form solution for any integral (although these skills, especially the integrals, can come in handy). Nor does it mean that you can memorize the Bellman Equation, or the Fundamental Equation of the Calculus of Variation. [Now the Fundamental Theorems of Calculus are different, and you should really know them!] Mathematical maturity means that your mind can handle definitions, their implications, and the logical steps to derive results. This is hard, because there is no rule, no procedure, no first-order condition to memorize. It takes experience, practice, and painful mistakes. 
You will have to understand what is meant by a proof. You will have to understand the difference between a definition and a result. You will have to embrace the power of logical reasoning. By and large, we don't need that much of very complicated logical reasoning in economics. However, you will be better off if you can think in a logical way, and that's when mathematical maturity can help you.

Sooner or later, your supervisor will say to you: "This sounds like good intuition, but it requires a proof." Or he or she may say, "You probably guess it right, and I am willing to bet that it's the right proposition. But you've got to prove it." Without the right mathematical background, you may have a problem! With the right background, you may be able to find the mathematical steps to prove it.

You can achieve mathematical maturity only by learning and doing---if you are not born with it, that is. So get ready, construct a lot of examples. Be ready to play tricks with definitions. Here is a riddle I want you to think about. A function is said to have an inverse if it is one to one and onto. We all know that a strictly monotone function has an inverse. Now construct a function on a continuous domain that is not monotone and yet it has an inverse! When you have done that, you really can see the difference between monotonicity and one-to-one-onto.

Do I seem like splitting hairs? Yes, I bet. But there is no uncertainty in mathematical statements. Either a function has an inverse or it has not; either a function is monotone or it is not. Is it really true that monotonicity and inversion are EXACTLY the same? Now you've got to be very careful. If you need to split hairs to prove a theorem, then that's the way to do it.

Now what about the repertoire of mathematics that you should learn? You must have heard of optimization with and without constraints, dynamic programming, nonlinear programming, fixed-point theorems, real analysis, functional analysis, differential equation, etc. Each one of these is a serious field of study. You will need to know at least a little of each.

In my own experience, analysis and calculus in $\mathrm{R}^{\mathrm{n}}$ have gotten me quite a long way. The most useful general ideas are choosing a function to maximize something under some constraints, the envelope theorems, and the maximum theorems. The two concepts in mathematics that I myself have found the most use turn out to be continuity and monotonicity, very basic stuff. Also, contrary to popular beliefs, in my experience, firstorder, second-order conditions and such formulas should be avoided; you should treat them as last resorts because they tend to promote mechanical thinking. I hate first-order conditions so much that once I set an exam in which every optimization problem had a corner solution!

The bottom line: do not get bogged down with mathematics. You should learn as much as you need. You should have some solid mathematical skills. Specific procedures for the optimization of a certain function subject to certain constraints are less important than the general way to think about constrained optimizations. Being able to think about functions 
like they are real objects will serve you very well. You can always find the exact Hamiltonian, or Euler equation from a book; their exact formulas are less important. Being able to visualize a certain function as a solution to a problem is much more valuable.

Now I want to say that mathematics is a very interesting subject, and you may think that it is an injustice to take a learn-as-you-need approach. But you are not doing a Ph.D. in mathematics. You may enjoy mathematics in your spare time, but you will hardly have any spare time in the next few years.

\section{A Manual for Ph.D. Research}

This is the 64 million dollar question. How does one do research? How does one come up with research ideas? Research is a multidimensional process. I am going to concentrate on only a few issues. But let me refer you to a paper by Hal Varian, "How To Build An Economic Model in Your Spare Time.” You will find lots of tips on coming up with good models and implementing your research. Well, I myself run out of ideas quickly. So you should take a look at Varian!

\section{Your Own Research Interest}

A long, long time ago, a very prominent economist said this to me, "There are those who aim to write papers that would be praised by others. There are those who do research on whatever they feel like doing, and they don't care a bit whether it is published or not." After a long pause, he said, "Most of us are somewhere in-between.” This is almost true as a tautology, hence not very useful. But it highlights one important thing. Your research topic must be something that interests you.

You must be enthusiastic to study a problem, analyze it, and solve it. If you want to be praised as the one who proves Riemann's Hypothesis, then you by definition are interested in the Riemann Hypothesis. And if the Riemann Hypothesis interests you even if you don't want to be praised, you will be motivated to work on it. (If you don't know what it is, let me just say that the Riemann Hypothesis tells you everything you want and need to know about the prime numbers. Since I am an economist, let me also mention that there is a US\$1million prize on the proof of the Riemann Hypothesis. And, by the way, the Riemann Hypothesis, first stated about 150 years ago, is likely to be harder than Fermat's Last Theorem, which took about 500 years.)

To work on something that you are not interested in is a real torture, and something that you cannot endure for very long. So you must find a topic that really interests you.

\section{How to Approach a Research Topic?}

What's the next step? You likely will find that some other folks have worked on the problem that you are interested in. So by all means find out a little bit about what has 
been done. But perhaps you do not want to find out too much. Your mind needs to think about this problem in its own way. Your mind should not be completely overtaken by existing ideas.

Now you have decided that you would like to work on something, say, interaction between physician and patient. And you have taken a quick look at the literature, perhaps keeping in mind what you have learned from the graduate health economics class. And you say to yourself that you want to do something about physicians who really care about their patients. What next?

You may want to talk to a faculty member. You should contact a professor who has had some experience in health economics, for example, and who has perhaps some interest in physician-patient interaction. Many things may happen after the first or second meetings. You may be asked to read more papers, or to formulate some hypotheses or models for analysis. Or you may be told that the topic is rather odd; maybe it is too mature for fresh ideas. Or that your particular approach is too arcane. But, the professor may also say that your ideas are interesting, refreshing, and likely to be revolutionary.

You should also talk to your classmates. Frequently students may be afraid to talk extensively with faculty. First, students fear that professors may not want to spend too much time with them. Well, professors are usually busy, and there may be occasions when professors cannot spend too much time with students. Second, students fear that professors are too intimidating. Indeed, speaking about rough ideas to experienced researchers usually results in quick criticisms. Of course, these criticisms may turn out to be useful, but nonetheless may discourage students, and professors may not be very sensitive to that. If you find talking with your classmates more comfortable, then by all means interact with them.

To continue let's say that you have somehow found the professor's response to be positive and that the avenue for research seems promising. Then you start working on the research!

\section{What Makes a Good Researcher?}

Work, hard work. I can be more specific. But perhaps it doesn't hurt to generalize. I think that two things contribute to the success of a Ph.D. (or even an academic career):

- Your intelligence

- Your work discipline

\section{$\underline{\text { Intelligence }}$}

Perhaps we all can agree that not much can be done about intelligence. The technical jargon is that the opportunity cost of changing intelligence is more or less infinity. You either have the minimum IQ for a Ph.D. or not; you either have the minimum IQ for an academic career or not. And changing one's intelligence seems awfully hard. 
There is, however, something that you should do about your intelligence. And that is to put it to full use. I think that the key is self confidence. If you have self confidence and self esteem, you can use your intelligence fully.

Self confidence and self esteem are difficult topics, well beyond my expertise as an economist. They are best discussed by real professionals such as psychologists and psychiatrists. I am not about to practice psychotherapy without a license, but can offer you some thoughts.

In my experience, people who lack self confidence say "I can't do this" often. They fail without even trying. Or they may try once or twice and then give up all too quickly. Conversely, people who are confident of themselves are not that worried about failing. How does one manage to say "I can do this.”?

Positive thinking helps. Here is something that happened to yours truly. A paper of mine got rejected by a leading journal. Rejection of a submission is common in our profession, so what's the big deal? The referee report was the most negative I ever got! In sum it said that my submission was not worth the paper it was printed on. Everything was trivial, and the use of mathematics a disgrace.

One could be devastated by such a negative report. I could have felt so depressed that working on the paper again would be very difficult. I might have said, "I can't deal with this anymore.” And the paper would then never see the light of day. But I decided on a positive interpretation. In fact, I thought that the referee was praising me! I wrote so well that the reviewer could understand all the arguments without going through the mathematics. I made the arguments so clear that they appeared trivial. It was the referee who was confused about clarity and triviality, and committed an error of judgment. I decided to submit it to another journal without much delay.

If I had stopped, if I had said to myself “I can’t deal with the paper any more,” nothing would have happened. But I decided that "I can deal with this paper.” Instead of saying, "I can’t do this,” I said, “I can do this.” A willingness to take risks may eventually build self confidence, which helps you to use your intelligence fully.

\section{$\underline{\text { Work Discipline }}$}

Well, some people like to think that work habit is like intelligence; it can't be changed. Let's say you work four hours a day, five days a week. That's your work habit, and nothing in the world can change that. So, again, not much to be said. But I don't think that this rigid scenario applies to everyone. Or to most of us.

Make no mistake about it. Doing research for a Ph.D. is hard work. I have no sympathy for students who party three, four days a week and want to write a dissertation in three, four or even five years. I have no sympathy for students who put priority of vacation over research progress but still want to publish a paper in Econometrica. 
Most important, it's your mind that is really doing the research. If you keep THINKING about party and holiday, how do you THINK about research? You really need your MIND to work full time, and that requires a focus that many, many people may be found wanting. Is this a 24/7 job? I wouldn’t say that much, but it is not much less.

In my many years in this profession, I have come across more than a few very intelligent economists whose research perhaps is somewhat ordinary. The only reason I can think of is that they don't particularly want to, or have decided not to, devote their mind power to the research task. I believe that work discipline is something that is entirely your decision. It is up to you to work hard.

\section{Dedication and Will Power}

The combination of the effective use of your intelligence and good work discipline actually translates to dedication and will power. In your research, you need to devote your mind to think about the problem you want to solve. You need to go deep, and explore possibilities that would come about only after long hours of thinking. And I emphasize thinking.

You need will power too. Research discovery is a Poisson process. The probability that you will discover something in the next instant is practically zero. You need to accumulate time, hours, days, weeks even, for a positive discovery, an example, a proof. Can you garner your will power to sustain this process? Can you handle the disappointment or frustration when for three, four, five months you can't show what you have wanted to show? You need will power to stay afloat in this business.

Furthermore, you may need to go over a discovery many times in order to polish it to "perfection." The first proof of a proposition may be long, tedious, and complicated. You need to simplify it, make it elegant, make the arguments flow smoothly. You may even need to find a new proof. This takes time and effort. Again will power, dedication, and persistence are what you need.

Many of you now think that research is a "challenge” like climbing Mount Everest. There is a moment of triumph when you reach the summit, and you know that you are at the top of the world. Yes, research is a challenge, but the outcome is never quite as clear cut as climbing Mount Everest. There is no research altimeter that says you are at 32,000 feet and there is no higher ground to climb. You may make progress along the way, but may not know if you have done all the best you can. You are climbing a mountain alright, but you have no map, or altimeter. And even when you think that you are there, having discovered something, you need to make it better. An attitude of relentless pursuit of excellence is critical.

Because research is very much a mind game, you should pay special attention to your mental health. Many people find it hard to work well when they are anxious, worried, or otherwise depressed. If you have mental health problems, then your mind will be thinking 
about its own problems, rather than economics. Just as you consult a physician when you have problems with physical health, you should consult a mental health professional when you believe that you have a mental health problem. Counselors, psychologists and psychiatrists are professionals who may help you. It is a sign of strength for someone to seek help. The weak will only hide and refuse to solve the problems. If you believe seeing mental health professionals is a taboo, that's wrong thinking.

Let me emphasize again. Your mind is what does the research. This is the driving force behind your discovery. You absolutely need your mind to work towards your research. There are many distractions. There may be personal issues that you will have to sort out. There may be financial issues that bother you. And you may become anxious about, say, living environment, pets, significant others, parents, friends. These distractions degrade your focus.

Unfortunately, I have no magic bullet to offer you here. It is a fact of life that there are issues and problems that you, and your mind, have to deal with. And sometimes these are not problems of economics research. At some point, you may want to relax, try not to be so hard on yourself. Make a decision about priorities. Sort out problems. You may decide that research is not the most urgent or critical thing for you to handle. That's perfectly ok, and nobody will think the lesser of you. It is a perfectly fine decision to set aside a Ph.D. in order to handle some other problems.

\section{Is there a Tradeoff between Intelligence and Work Discipline?}

You might have thought that I would say, no, there is no tradeoff. But surprisingly I think that there is. It's a tradeoff that, I believe, favors work discipline. I am willing to give up quite a few IQ points for a superior work discipline. I am willing to be less smart, less sharp, less quick, in order to be able to concentrate on a problem for a longer period of time, and to focus more intensely on a research topic.

I bet that, unless you are talking about the very, very top pioneers, the difference in intelligence among most academics must be very small. What makes a good researcher is one’s ability to lock the mind onto one problem. "Keep going," “just keep going,” "keep thinking about it," “don’t give up.” These will serve you very well. Sir Peter Medawar, a British Nobel laureate biologist was quoted as saying, "One does not have to be terribly brainy to be a good scientist," and "One would do better for owning some of those oldfashioned virtues---application, diligence, a sense of purpose, the power to concentrate, to persevere and not to be cast down by adversity."

And there is one other very important reason why I favor work discipline over intelligence. This is a factor that likely only has a marginal effect on you, but I should mention it here. It is experience. You will not appreciate it yet, but research experience matters a lot, a whole lot. If you have good work discipline, you work better, and you accumulate research experience. It's a snowball effect. More research experience helps with future research. I will come back to experience a little later. 


\section{Writing Your Thesis}

This is exactly the skill that no economics graduate school will teach you, and so I deem it my real responsibility to mention it here. Let me state it very simply. Writing a paper requires a lot of skill and experience that most graduate students simply don't have. For so many years, I have wondered why graduate schools in the world do not include critical writing as a required course!

Here are the most common mistakes found in dissertations:

- This is the history of my research. Everything that I did is included.

- Here are my thoughts on the research topic, in no particular order.

- The pages to follow contain the chaotic calculations required to prove the results.

- The sentences are incomprehensible; the flow of the argument is like the many small rivers going through the fjords, very steep, very hard to see, and disorganized.

- You read this at your own expense of hiring an English (or any other language) editor.

What do you want to do when you feel like you have all the results? Naturally, you want to write them up, and have a paper, a chapter of your thesis. Writing it up is exactly the wrong attitude. Good writing is good thinking. Clear writing is clear thinking. Critical writing is critical thinking. Good writing is a skill that requires practice, training, and, yes, thinking. Just writing it up is going to be a disaster.

Even many published papers are poorly written. Haven't you read this sequence before in published papers? "Roughly, the intuition is this..." "More precisely, the argument is that..." "Finally, formally, the mathematics goes like this..." This is exactly what bad writing is like. What is the point of a convoluted way of stating your ideas? Presenting your model, arguments, and results is not leading your reader on a wild goose chase.

Let me make a few analogies. What do you think trial lawyers do when the detectives, clerks or assistants have gotten them all the "facts" of the case? What do you think movie directors and producers do when the shooting is done? What do you think newspaper and magazine editors do when they have received all the scripts from authors or wire services?

They have to do a lot of work to present whatever they have in a motivated, coherent, convincing, and clear way. They cut, request revisions, demand elaborations, and organize. Much work needs to be done before the final product is ready. The editorial process requires a lot of work.

Scientific writing has one and only one goal, and that is to present the ideas and results precisely, without any possibility of confusion and misunderstanding. To do that requires a lot more work than most graduate students can even begin to contemplate. What's 
more, writing a paper requires on-going research. If I spend six months "proving” the results I want to find, I expect to spend another six months "writing them up.” Why? Because when I write a paper, I always have to adjust the results, prove new stuff, think about the motivation even more, organize the results in various, combinatorial fashions, and engage in endless rounds of "relentless pursuit of excellence."

Moreover, you need to work on the manuscript in ways that you cannot even imagine now. What may have been a part of Section 3, after some thought and work, may be more suitable to be in Section 5. You need to iterate back and forth between sentences, paragraphs, sections to find the right approach. Your goal is to present your ideas in the clearest and most attractive way.

How do you become a good scientific writer? Hard work, no doubt, you say. That is absolutely true. But this is hard work that requires the kind of training unavailable from economics classes that you will attend. You need some specialized training in writing skills. And it is unlikely to come from Topics in Advanced Economic Theory or Econometrics. Check out the English department.

I can't possibly share with you experiences about writing in a lecture. But there is plenty out there that you can resort to. You can even begin by being a good reader. Notice how good scientific writers do their job. Notice how easy it is to read papers that are well written. Notice how clear the arguments are when they are made by a good writer. On the other hand, be critical. When you read a paper, think about how you can improve it. Can the arguments be presented differently? Can the points be made more clearly? Can you rewrite some of the sentences, or paragraphs to improve them?

Whether you like it or not, whether you think it is fair or not, the majority of economics papers are to be published in English. It follows that English is the language in which you will express your economics. Therefore, it pays to learn English well. Norwegians already are ahead in the game since they speak good English. Let me say, however, that there is some difference between spoken English and written English, especially the scientific kind. You should pay special attention. Even native English speakers may be poor English writers!

I cannot go on with writing skills. Let me mention a few books. There is the classic "Elements of Style" by Strunk and White. (Yes, E.B. White, the author of Charlotte's Web. Have you seen the movie?) Strunk and White was written almost a hundred years ago (a little bit exaggerated), but it's so strikingly relevant even today. Strunk and White is also very elementary. The stuff in there is something you MUST know.

Then there is "Economical Writing” by McCloskey. This little book is written by an economist for economists. Obviously the book itself is very well written. McCloskey also has written many other books. Reading them will make you appreciate what good economics writing is all about. I have read "Economical Writing" many times, and often I would disagree with the author. That, I guess, is a good sign. If I can disagree, it means that I have thought about those issues. Again, good writing is good thinking. 
Finally, let me mention “A Guide for the Young Economist” by Thomson. This book is more general, as the title suggests, than just writing. But I thought that this is the right place to bring it up. It includes many tips and suggestions for young minds.

If you have no idea that "writing up" your thesis requires skills, well that's a rude awakening. But since you are only just beginning, you have plenty of time to acquire those skills.

\section{What Your Supervisor Can and Cannot Do for You}

You must feel happy that you are going to have a thesis supervisor. You should be glad that you will do research with guidance. It may also be a very nice experience since you may interact with another beautiful mind.

Now you may or may not have more than one supervisor. And you may work with someone who is not officially your supervisor. For the purpose of this talk, I am going to ignore these details. Let me ASSUME that you have one supervisor. (Now if you appreciate this assumption, you are beginning to think as an economist. By the way, an assumption should always buy you something at a reasonable cost. Otherwise, don't make it. So think about what this assumption does buy me, and what is its cost.)

Your supervisor is very likely the most important person to help you with your Ph.D. research. There is a first principle about your supervisor that I would like you to know. Yes, your supervisor is an economist, and a professor. But Ma's first principle is that your supervisor is human. Remember that your supervisor also has to do grocery shopping, plan for vacations, fix the toilet, and cook dinners. Two things about humans you must recognize: they are all very different, and none of them is perfect.

\section{Your Supervisor’s Mind}

Human beings exhibit a lot of diversity: they have different genders, races, ages, physiques, demeanors, personalities, etc. Human beings' minds can be very different. Even economists, who share some common intellectual traits, language, and background, have minds that operate in their unique ways. You should try to understand how your supervisor thinks. You should try to understand your supervisor's style. Read a couple of your professor's papers, especially working papers. Try to understand what ideas are occupying your professor's mind.

Here is an example. I like graphs, and I can't remember Kuhn-Tucker conditions. So when I have a constrained optimization problem, I draw some pictures, or try to figure out which constraints are binding. That's how I think about it. When a student gets stuck with such a problem, that is how I would try to help. Now suppose that a student has a problem that is absolutely 10-dimensional, and there are 15 inequality constraints so complex that graphs and guesses are not useful, I can't be of much help. But another 
professor who absolutely adores Mathematica or Maple, or any other artificial intelligence program may handle it in stride. And if your research must involve 10dimensional-15-inequality-constraint problems every day, even if it is in health economics, I would not be interested. Nor can I be very helpful.

Let me give you another example. When I write a paper, I use short sentences, many paragraphs. I hate writing a paper longer than 30 pages. I would use double spacing between lines. Naturally I would steer my students to write short sentences, separate ideas into short paragraphs, and avoid papers that are too long. It would be useful if my students would consider this style when working with me.

\section{It's an Imperfect World}

The next thing you must recognize is that human beings cannot be perfect. We all have our own shortcomings, be they intellectual, personality, or demeanor. You must learn to work with an imperfect supervisor; likewise, supervisors, I think, would have to work with imperfect graduate students. The important words are "work with.” Working with someone means compromise, communication, and recognizing weaknesses and strengths.

Does it sound like a skill in interpersonal relationship? Yes, indeed, it does. You do well acquiring some skills in interpersonal relationship. Because you need to intellectually connect with your supervisor, communication is the key to that connection.

I believe that the key to successful communication is mutual respect. You and your supervisor should take each other seriously. You will likely hear suggestions from your supervisor. Think about them before you agree or disagree. Pay some attention. This effort actually helps to establish your supervisor's respect for you.

Your supervisor should also recognize your strength and weakness. You can also bring to your advisor's attention your own strength and weakness. That will help. You must remember, however, that thesis supervisors tend to be pushy. They tend to be demanding, asking for more, wanting a better paper all the time. This is a professional habit that you simply cannot change. After all, this relentless pursuit for excellence has helped most professors to survive in academia. Sometimes they may forget that it is unproductive to ask students to do what they can't or wouldn't do. If you find your professor too demanding, raise your concern. Speak about your limited ability. Letting your supervisor know about your weakness can only help you.

Let me list a few things that your supervisor cannot do for you.

- Your supervisor cannot write your thesis.

- Your supervisor cannot always make correct conjectures.

- Your supervisor cannot check the proof of every proposition or verify every test.

- Your supervisor cannot correct all grammatical errors.

- Your supervisor cannot know all the literature. 
You probably wished that your thesis advisor could do all the things I have listed above. Remember, we live in an imperfect world. No supervisor can provide all the things above. Most supervisors cannot even provide one of these!

Let me emphasize that you will have to find the right supervisor. What would happen if you found the wrong supervisor? For example, if you are interested in macro and somehow you keep talking with me, maybe about calibration or high-order differential equations, and somehow I have failed to kick you out of my office, then you will be wasting your time. You see, Ph.D. research is quite specialized. You must have a common research interest with your supervisor to embark on a fruitful research relationship.

Finally, what should you do if you feel that working with your supervisor has been a mistake? Suppose your progress is unsatisfactory. It appears to you that it has not been a good match between yourself and the supervisor. And you believe there is no more help from your supervisor.

You should decide to change to a different supervisor if the work relationship is not helping you in any way. Your supervisor is being paid to guide you, and if the match is unsatisfactory, you should find another. You might fear that this would make your supervisor angry, and might even jeopardize your career! I can't speak for others, but for myself, there is no better news than a student telling me that he or she wants to work with somebody else! It means that I get paid but having to do no work! More important, I have one less thesis to worry about! If you have any concern, talk to your supervisor openly and in a courteous manner. You will likely find that professors are reasonable people.

\section{Experience}

Now your ask, what is it that you can expect from your thesis advisor? I would say that the most valuable benefit you can get from your supervisor is his or her experience, which I touched upon a little earlier.

Sometimes your supervisor may give you a problem to work on. Or you may have started on a problem on your own. But as the research continues, there will be decisions to make. No theoretical model is perfect. No data set is complete. You always have to make compromises. Your supervisor has made many such decisions before.

It may take you three weeks to find out that an assumption is either too strong or too weak. But your supervisor may be able to tell you that in a couple of hours. Why? Because some years ago, your supervisor was in a similar situation and did take three weeks to find that out! You see, economists don't believe in free lunch, but they have to believe that sharing research experience is rather free.

You will often read or hear about "standard" ways of solving a model. As you study research papers, you realize that they are not nearly standard! The mathematical details are long, or the statistical properties difficult to state. How can they be standard? You ask 
your supervisor about them, and then you are surprised when your supervisor says that these are standard methods. Why? Because your supervisor has probably used these complicated procedures hundreds of times. Familiarity breeds skills. So your thesis advisor can guide you through problems by telling you, for example, that there are standard ways to handle them.

Let me talk about another aspect of experience. You think you have an interesting problem, and spend three months trying to prove a major theorem. After three months, you are exhausted, disappointed, and realize that either the proof isn't right or the theorem isn't true. Here again your supervisor might have helped. Your professor can likely tell you whether some theorem sounds too good to be true, or requires a proof that has eluded researchers for decades. Why? Again, your professor might have experienced the same pain before.

Experience helps one to spot promising results, avoid mistakes, draw a connection between your current research and known results, and recognize that a research agenda is hopeless. You, as a graduate student, lack experience. Your supervisor has a lot more experience. If you do not make use of your supervisor's experience, what kind of an economist are you (or will you become)?

\section{Collaboration}

The work relationship with your supervisor may be so good that you decide to write a paper together. You feel very excited to be able to do this. This will be a very rewarding experience for you. Now you have a first-hand experience to see how a real professional handles a problem, finds solutions, writes the paper, deals with journals, etc.

Joint authorship has become very common in economics. If I have five active projects, I may have $\mathrm{N}$ coauthors, where $\mathrm{N}$ may be between five and ten! It is truly a very rewarding experience to collaborate with a fellow economist. I strongly encourage you to try it.

There is one thing I must warn you though. The market is a search engine for talents. Joint authorship, by definition, contaminates the revelation of information. The technical jargon is signal-jamming. When you collaborate with someone who is much more senior, the rest of the world may downgrade your contribution. In a sense your supervisor may become a signal-jamming agent. This is insignificant if you have 10 coauthors and 5 of them are more senior. But if you have written one and a half papers and one of them is with your supervisor, then perhaps the market may become confused.

I do not want to exaggerate this signaling issue. The market will filter out the noise. If you are good, I believe that the market eventually will recognize it. It is such a satisfying experience working with a senior economist that I myself would never hesitate. There is, however, a way to avoid signal jamming when you work with others at the beginning of your career: collaborate with someone in your own cohort, such as a classmate. You will find this a very rewarding experience too. The rest of the world will hardly have any reason to doubt your contribution. 
The Last Laughs

What do you think is the most "serious" complaint made by professors against their students? You might have thought it must be "they are lazy," "they are not very smart," or "they are slow." I have heard these complaints before, all of them. But the one complaint made by professors against students that almost always is expressed with disappointment and sometimes even anger is “They don't listen!”

Your supervisor is usually heart-broken when you learn it the hard way. He might shake his head and said that if you had listened, things might have been better. Here, I think perhaps professors also have something to learn. Many students can ONLY learn it the hard way. Somehow, for some learners if the disutility of a mistake is low, the experience becomes trivialized, and it doesn't stick to the mind. The mind does remember painful experiences, however.

You may decide to ignore your advisor's suggestion of a better introduction to the paper. You submit the paper to a journal, as is. A few months later, the rejection letter arrives, and it says that the introduction is poorly written. Now in your revision, you really spend some time and effort to write a good introduction. Why? Because ignoring your advisor's suggestion doesn't seem to carry any immediate penalty, while the paper getting rejected by a journal is a painful experience.

Here I am a professor. So I can’t help but say, “Make an effort to listen to your professors. It might just pay off.”

\section{A Journey for Your Mind}

And so I have told you a little about modern economics and graduate study and research. It will be a journey for your beautiful mind. It is an experience for the privileged few. Only a small percentage of people gets to work on a Ph.D. You should understand that you are doing something that most of the general population never gets to experience.

What are the goals in your graduate study and research? I think that there are two. First, you have an opportunity to add to knowledge of economic science. Second, and I think this is actually more important, you have an opportunity to learn to become an independent researcher.

The first goal is obvious. You need a thesis to graduate. Your dissertation should be a significant contribution to economic science, and you have to do that to earn your degree.

The second goal is more general. You may or may not want to continue in the academic profession. You may choose to do things other than economics after your Ph.D. In fact, many people with economics Ph.D.s are working in areas totally unrelated to economics. But these do not change the nature of your graduate study. You are learning to become 
independent researchers. And I stress "INDEPENDENT." Independence is part of maturity. As your mind grows and becomes mature, you will realize that this journey for your mind will indeed be an important part of your life.

I have not described a very easy journey ahead of you. I have mentioned hard work many, many times. Moreover, your department and professors offer you no guarantee. But then you have to realize that most good things in life require hard work, and don't come with any guarantee.

Adding to the existing knowledge of economic science, and becoming an independent researcher are all tremendously difficult, even risky, and require great efforts. But it is all very satisfying. I have had such a wonderful experience that I would do it again. So let your beautiful mind go on this journey. 


\section{References}

McCloskey, Deirdre N., Economical Writing, Waveland Press, Illinois, 2000.

Sen, Amartya, "Rational Fools: A Critique of the Behavioral Foundations of Economic Theory,” Philosophy and Public Affairs, Vol. 6, No.4 (Summer 1977), 317-344.

Strunk, William Jr., and E.B. White, The Elements of Style, Fourth Edition, Pearson Education Company, Massachusetts, 2000.

Thomson, William, A Guide for the Young Economist, MIT Press, Masschusetts, 2001.

Varian, Hal, “How To Build An Economic Model in Your Spare Time,” in Passion and Craft: Economists at Work, Michael Szenberg (ed), University of Michigan Press, 1997. 